\title{
Torsion of preterm gravid uterus: A case report
}

\author{
Sabuhi Qureshi, Uma Singh, Bhumika Bansal, Nisha Singh
}

\begin{abstract}
Introduction: Rotation of the gravid uterus is a normal occurrence in the third trimester of pregnancy. However, a pathologic rotation of the uterus beyond 45 degrees i.e, torsion of the entire uterus-is rarely encountered. We report here a case of uterine torsion from our obstetrical practice. Case Report: A young 25year-old second gravida, para one presented with features of antepartum hemorrhage (Abruptio placentae) with intrauterine fetal demise at 25 weeks of pregnancy. During laparotomy uterine torsion of 180 degrees was diagnosed. As all attempts at detorsion failed, a deliberate posterior lower segment incision was made to deliver the baby. Subtotal hysterectomy had to be done as conservative procedures (utertonics, uterine artery ligation, B-Lynch suture) to control postpartum hemorrhage failed. The patient was recovering in the postoperative period, when she died unfortunately of a suspected pulmonary embolism. Conclusion: Uterine torsion is an
\end{abstract}

Sabuhi Qureshi ${ }^{1}$, Uma Singh ${ }^{2}$, Bhumika Bansal ${ }^{3}$, Nisha Singh ${ }^{4}$

Affiliations: ${ }^{1} \mathrm{MS}$, (OBGYN), D.N.B (OBGYN), Associate Professor, Dept of OBGYN, CSM Medical University, Lucknow, UP, India; ${ }^{2} \mathrm{MS}$, (OBGYN), Professor and Unit head, Dept of OBGYN, CSM Medical University, Lucknow, UP, India; ${ }^{3}$ MBBS, Junior resident, Dept of OBGYN, CSM Medical University, Lucknow, UP, India; ${ }^{4} \mathrm{MD}$, (OBGYN), Professor, Dept of OBGYN, CSM Medical University, Lucknow, UP, India.

Corresponding Author: Sabuhi Qureshi, G-36, Sanjaygandhi Puram, Faizabad Road, Lucknow, Uttar Pradesh, India - 226016; Ph: 0522-2311192; Mob: 09450712485; E-mail: sabuhikgmu@yahoo.co.in

Received: 30 August 2012

Accepted: 15 May 2013

Published: 01 July 2013 infrequently reported and potentially dangerous complication of pregnancy that occurs mainly in the third trimester with adverse maternal and neonatal consequences. Aetiopathogenesis of this condition is still unclear. The diagnosis is usually made at laparotomy. Often posterior lower segment incision is used for delivering the baby. It merits consideration as a differential diagnosis of acute abdomen in pregnancy.

Keywords: Torsion uterus, Gravid uterus, Preterm gestation

$* * * * * * * * *$

Qureshi S, Singh U, Bansal B, Singh N. Torsion of preterm gravid uterus: A case report. International Journal of Case Reports and Images 2013;4(7):392-395.

$* * * * * * * * *$

doi:10.5348/ijcri-2013-07-339-13

\section{INTRODUCTION}

Torsion of the gravid uterus is a rare potentially serious, unexpected obstetric pathology and is almost always diagnosed at cesarean section [1]. We present a rare case of uterine torsion at preterm gestation.

\section{CASE REPORT}

A 25-year-old female, residing in a rural area was admitted in emergency of a tertiary care hospital with decreased fetal movements and bleeding per vaginum since one day following amenorrhea of six months. She had fresh bleeding and had soaked six pads. The 
bleeding was accompanied by mild pain in abdomen, continuous, dull aching with no radiation. She was not booked as an ante-natal case at any hospital and this was her first hospital visit in this pregnancy. In her obstetric history, she had a full term vaginal delivery of a female stillborn baby, cause of which was not known. Rest of her past history, medical, surgical and personal was not significant. On general examination, she was conscious and oriented to time, place and person with severe pallor, feeble and hypovolumic pulse of 120/ minute, blood pressure $100 / 70 \mathrm{mmHg}$ and temperature of $38^{\circ} \mathrm{C}$. Systemic examination revealed tachypnea and crepitations in lung bases.

On abdominal examination, there was abdominal wall edema, fundal height of 30-32 weeks (which was more than the period of gestation). As the uterine tone was increased, exact fetal lie and presentation could not be assessed. Fetal heart sound was absent. Internal examination revealed unripe closed cervix. A diagnosis of gravida two para one, 25 weeks 1 day pregnancy with intrauterine fetal demise, abruption placentae, severe anemia and pulmonary edema was made.

Abdominal ultrasound showed a singleton intrauterine pregnancy with fetal demise with an upper segment placenta. Her blood investigations revealed a normal coagulation profile with deranged kidney function (Blood Urea $102 \mathrm{mg} / \mathrm{dL}$, Sodium creatinine $2.5 \mathrm{mg} / \mathrm{dL}$ ) and severe anemia $(7 \mathrm{~g} / \mathrm{dL})$. Urinary albumin was present in traces (dipstick method). After stabilizing her condition, she was taken up for an emergency cesarean section in view of abruption placentae with unfavorable cervix as vaginal delivery was not imminent. On opening the abdomen (by an infraumblical midline vertical incision), the uterus was seen completely rotated on its axis; by 180 degrees. The fallopian tubes and ovaries were lying anteriorly (Figure 1). Uterus was extremely enlarged filling the whole abdomen till epigastrium. Uterus, tubes and ovaries were bluish in color. With all attempts at detorsion failing, uterus was opened by a lower segment posterior incision. Baby was macerated stillborn, weighing $800 \mathrm{~g}$. Placenta was lying completely separated. It was removed with all membranes and cotyledons with approximately $700 \mathrm{cc}$ of retroplacental blood clots. After delivering the baby and placenta, detorsion of the uterus was done. Active management of third stage of labor was done by administration of 10 units syntocinon (oxytocin, novartis) intramuscularly. Despite this the uterus did not contract, instead it was flabby, enlarged, bag like and couvelaire. Aggressive administration of other uterotonics was done but the uterus remained flabby. Bilateral uterine arteries were ligated and BLynch sutures were applied subsequently. As the uterus did not respond to these, decision for subtotal hysterectomy was taken. Intra-abdominal drain was put after performing subtotal hysterectomy. Abdomen was closed in layers after confirming hemostasis. Peroperatively, the patient's hemodyanamic condition deteriorated.

Vasopressor support and packed red blood units were given. Postoperatively, the vasopressor support

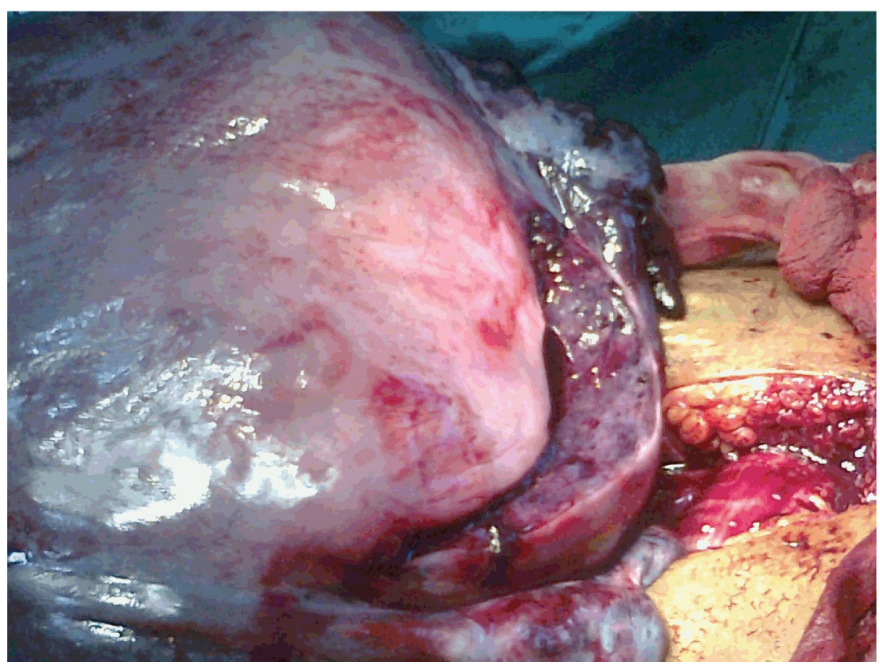

Figure 1: Posterior surface of uterus is seen with cesarean incision. Posterior surface is identified by attachment of ovarian ligament lateral to incision site. Deliberately, the cesarean incision was given on posterior surface of uterus.

was continued and as the patient stabilized, it was gradually tapered by the second postoperative day. The patient was recovering satisfactorily but had an episode of sudden pain in chest followed by breathlessness on third postoperative day. A probable diagnosis of pulmonary embolism was made. Unfortunately, the patient died before the diagnosis could be confirmed.

\section{DISCUSSION}

Torsion of the gravid uterus is defined as rotation of uterus, around its long axis of more than 45 degrees [2]. Torsion from 60 degrees to 720 degrees has been described $[3,4]$. Dextrorotation occurs in two-thirds of these cases and levorotation in rest of the one-third cases. Although the condition is rare in humans, torsion is observed in all age groups of the reproductive period, in all parity groups and at all stages of pregnancy [3]. Etiology is still unclear though several conditions are associated with it like abnormal fetal presentations, myoma uteri, malformations of uterus, adhesions and adnexal mass [5]. Robinson and Duvall proposed that certain maternal irregular body movements or posture and positions may help trigger the rotation of uterus with pre existing structural pathology. Intrinsic pathology is found in $66 \%$ of cases of uterine torsion [6].

The mechanism of torsion can be explained by an elongated cervix with structural weakness and angulation in the isthmic region leading to torsion. The structural weakness may be developmental or acquired [7].

In our patient, although there was no structural anomaly but abruption placentae was associated with it. This brings out an unanswered query of etiology of torsion. Is abruption placentae cause or effect of torsion uterus?

The clinical presentation of torsion is nonspecific. The most common symptom is abdominal pain. 
However, this may vary from nonspecific mild abdominal discomfort to symptoms of an acute abdomen with shock.

Some patients of uterine torsion may also present with abnormal fetal heart rate, failure to progress in labor [3]. In around $11 \%$ of cases, torsion is asymptomatic [8]. Establishing clinical diagnosis of torsion is thus difficult before laparotomy. Most of the reported cases in literature of uterine torsion have not been detected before labor or cesarean section. Our patient also presented with features of abruption placentae, intrauterine fetal demise and the diagnosis was made peroperatively.

As far as imaging is concerned, to make a diagnosis of torsion, ultrasonographic scanning is insufficient. Magnetic resonance imaging is the investigation of choice if torsion is suspected before cesarean section [3]. Patients with acute symptoms or with suspected uterine torsion should have a laparotomy. If the torsion can be corrected, anterior uterine incision should be given after correcting torsion. Posterior lower segment cesarean section is preferred for irreducible torsion with correction of torsion being done following delivery [9]. Plication of lax uterosacral and round ligaments is also suggested by some authors in literature to prevent retorsion [3]. Any predisposing factor such as adhesions, fibroids or ovarian cyst should be removed to prevent postpartum recurrence. It is also important to note the position of round ligaments anteriorly before giving the incision in the uterus and to correct the rotation if there is one. If rotation or torsion is not identified, the incision would be given inadvertently in lateral wall of uterus leading to hematoma formation.

Torsion of uterus is associated with significant mortality and morbidity. Overall the maternal mortality is around $13 \%$ and is directly proportional to the duration of gestation and degree of torsion [10]. Fetal mortality rates reported with the condition are 18\% [2]. Unfortunately, in present case the patient died after recovering from torsion uterus and the baby was still born.

For future pregnancies, as the risk of uterine rupture with a prior posterior lower segment incision compared with the risk following an anterior lower segment incision remains unknown, cesarean section is recommended.

\section{CONCLUSION}

Uterine torsion though a rare occurrence still merits consideration as a differential diagnosis of acute abdomen in pregnancy especially with sudden onset shock or vaginal bleeding unexplained by other common obstetric conditions.

$* * * * * * * * *$

\section{Author Contributions}

Sabuhi Qureshi - Conception and design, Acquisition of data, Analysis and interpretation of data, Critical revision of the article, Final approval of the version to be published

Uma Singh - Conception and design, Critical revision of the article, Final approval of the version to be published Bhumika Bansal - Acquisition of data, Analysis and interpretation of data, Drafting the article, Final approval of the version to be published

Nisha Singh - Conception and design, Critical revision of the article, Final approval of the version to be published

\section{Guarantor}

The corresponding author is the guarantor of submission.

\section{Conflict of Interest}

Authors declare no conflict of interest.

\section{Copyright}

(C) Sabuhi Qureshi et al. 2013; This article is distributed under the terms of Creative Commons attribution 3.0 License which permits unrestricted use, distribution and reproduction in any means provided the original authors and original publisher are properly credited. (Please see www.ijcasereportsandimages.com/copyright-policy.php for more information.)

\section{REFERENCES}

1. Albayrak M, Benian A, Ozdemir I, Demiraran Y, Guralp O. Deliberate posterior low ttransverse incision at caesarean section of a gravid uterus in 180 degrees of torsion: a case report. J Reprod Med 2011 Mar-Apr;56(3-4):181-3.

2. Wilson D, Mahalingham A, Ross S. Third Trimester Uterine Torsion: Case report. J Obstet Gynaecol Can 2006;28(6):531-5.

3. Jensen JG. Uterine Torsion in Pregnancy. Acta Obstet Gynecol Scand 1992 May;71(4):260-5.

4. Sparic R, Pervulov M, Stefanovic A, et al. [Uterine Torsion in term Pregnancy]. Srp Arh Celok Lek 2007 Sep-Oct;135(9-10):572-5.

5. Carbonne B, Cabrol D, Viltart JP, Papiernik E. [Torsion of the pregnant Uterus]. J Gynecol Obstet Biol reprod (Paris) 1994;23(6):717-8.

6. Robinson AL, Duvall HM. Torsion of the pregnant uterus. J Obstet Gynaec $\mathrm{Br}$ Commonw 1931;38:55-84.

7. Dua A, Fishwick K, Deverashetty B. Uterine Torsion in Pregnancy: A Review. The Internet Journal of Gynecology and Obstetrics 2006;6(1).

8. Jenson JG. Uterine torsion in pregnancy. Acta Obstet Gynecol Scand 1992 May;71(4):260-5.

9. De Ioris A, Pezzuto c, Nardelli Gb, Modena AB. Caesarean delivery through deliberate posterior hysterotomy in irreducible uterine torsion: case report. Acta Biomed 2010 Sep;81(2):141-3.

10. Nesbitt RE Jr, Corner GW Jr. Torsion of the human pregnant uterus. Obstet Gynecol Surv 1956 Jun;11(3):311-32. 
Access full text article on other devices

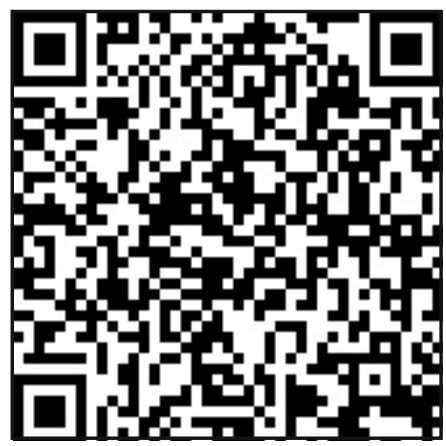

Access PDF of article on other devices

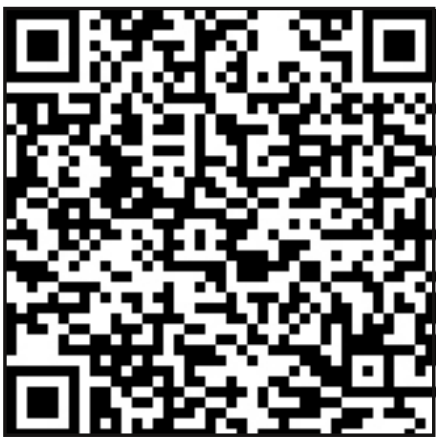

